\title{
SEJARAH MUNCULNYA PEMIKIRAN ISLAM LIBERAL DI INDONESIA 1970-2015
}

\section{THE BIRTH OF LIBERAL ISLAMIC THOUGHT IN INDONESIA 1970 - 2015}

\author{
Samsudin dan Nina Herlina Lubis \\ Universitas Padjajaran, Indonesia \\ E-mail: samsudin@uinsgd.ac.id,nina.herlina@unpad.ac.id \\ Naskah Diterima: 15 April $2019 \quad$ Naskah Direvisi: 20 September $2019 \quad$ Naskah Disetujui : 28 September 2019
}

DOI: $10.30959 /$ patanjala.v11i3.522

\begin{abstract}
Abstrak
Kemajuan yang dicapai oleh negara Barat dalam bidang ilmu pengetahuan, teknologi, dan ekonomi, berakar pada trilogi liberalisme, pluralisme, dan sekularisme. Atas dasar itulah, beberapa tokoh Islam Indonesia ingin memajukan umatnya dengan trilogi tersebut. Dalam perjalanannya, tokoh Islam seperti Nurcholish Madjid dan Ulil Abshar menuai kritik dari Rasjidi dan Atiyan Ali. Puncaknya adalah ketika MUI mengeluarkan fatwa mengharamkan Islam liberal. Bagaimana gambaran sejarah masuk Islam liberal di Indonesia? Mengapa terjadi polemik Islam liberal di Indonesia? Untuk menjawab pertanyaan tersebut, metode yang digunakan adalah metode sejarah, meliputi heuristik, kritik, interpretasi, dan historiografi. Berdasarkan hasil penelitian, sejarah Islam liberal di Indonesia terbagi ke dalam empat tahap, yaitu: Tahap awal ketika masih menyatu dengan pemikiran neo-modernisme. Kedua, pembentukan enam paradigma Islam liberal. Ketiga adanya kritik dan evaluasi pemikiran Islam liberal. Kemudian sebab terjadinya polemk pemikiran Islam liberal disebabkan oleh perbedaan paradigma berfikir dan metodologi memahami ajaran Islam dalam melihat realitas yang terjadi di masyarakat pada masa kontemporer.
\end{abstract}

Kata kunci: Islam liberal, sejarah, tokoh liberal, polemik.

\begin{abstract}
The progress achieved by Western countries in the fields of science, technology and economics is rooted in liberalism, pluralism and secularism. For this reason, some Indonesian Muslim intellectuals want to reform their people accordingly. However, in working with these modern ideas, the polemics arose as those Muslim scholars such as Nurcholish Madjid and Ulil Abshar were criticized by Rasyidi and Atiyan Ali. This caused the MUI to issued a fatwa forbidding Liberal Islam. This study addressed two questions: How did liberal Islam come to Indonesia? Why did liberal Islam polemic occur in Indonesia? The method employed in this study is historical method which is comprised of heuristics, criticism or analysis, interpretation, and historiography. The result of the study shows that the history of liberal Islam in Indonesia was developed into four stages. First, when the thought of liberal Islam was still integrated with neomodernism. Second, the establishment of six liberal Islam paradigms. Third, the emergence of criticism and evaluation toward it. Fourth, the polemic of liberal Islamic thought was caused by different paradigms and methodology in understanding the teaching of Islam that is compatible with the needs of contemporary society.
\end{abstract}

Keywords: liberal Islam, history, liberal Islamic scholar, polemic. 


\section{A. PENDAhuluan}

Secara etimologi, kata 'liberal' berasal dari kata liberte dalam bahasa Prancis dan liberty dalam bahasa Inggris yang berarti kebebasan atau kemerdekaan. Secara epistemology, liberalisme adalah paham yang berusaha memperbesar wilayah kebebasan individu dan mendorong kemajuan sosial. Manusia memiliki kebebasan dalam landasan pemikirannya dan mampu untuk bertindak sesuai dengan apa yang diinginkannya. Tetapi kebebasan yang dimaksud yaitu kebebasan yang bertanggungjawab karena tanpa adanya sikap tanggungjawab, tatanan masyarakat liberal tak akan pernah terwujud (Rachman, 2018:321-322; Echols dan Shadily, 1987:356).

Selanjutnya gagasan liberalisme diilhami oleh ilmuwan Prancis, yaitu: Voltaire, Montesquieu, dan J.J. Rousseau. Semula liberalisme merupakan gerakan pemikiran yang kemudian berkembang menjadi gerakan politik saat meletusnya Revolusi Perancis pada 1789 yang terkenal dengan semboyan; liberte (kebebasan), egalite (keseteraan), dan fraternite (persaudaraan). Pasca revolusi, paham liberal disebarluaskan ke negaranegara Eropa, Amerika, dan Afrika (terutama Mesir) (Nasution, 1975: 28; Azra, 1986: 27).

Pada 1886 patung liberty dijadikan simbol kebebasan masyarakat di Amerika Serikat. Menurut Azyumardi Azra, itu adalah hadiah Prancis untuk Masyarakat Amerika Serikat dan juga mengukuhkan persahabatan kedua negara. Akarnya dapat dilihat dari sejarah perjuangan masyarakat New England (Amerika Serikat) untuk membebaskan diri dari Inggris. Saat itu, Prancis yang membantu para pejuang kemerdekaan menggunakan Liberty dengan patung obor pembebasan sebagai simbol kebebasan. Simbol tersebut mengandung arti sebagai harapan bagi para imigran yang tiba di pelabuhan di New York agar terbebas dari tekanan hidup di tanah asalnya sehingga dapat mewujudkan the American Dream (Azra, 1986:27).
Selain tersebar ke Eropa dan Amerika Serikat, gagasan liberalisme juga menyebar ke Mesir melalui ekspedisi Napoleon Bonaparte. Mesir menjadi titik temu pemikiran Islam dengan liberalisme. Kemudian muncullah sebutan Islam liberal.

Islam liberal berarti paham Islam yang akomodatif terhadap ide kebebasan individu untuk mendorong kemajuan sosial. Menurut Kurzman (2003:xxxiii), Islam liberal adalah gaya berfikir yang merupakan perkawinan paripurna antara trio filsafat kritik dialektis Socrates (470400M) dengan rasionalitas Descartes (1596-1650) dan dipadukan dengan pemikiran Muktazilah (Rachman, 2018: 41). Istilah Islam liberal juga seringkali digunakan oleh para penulis Barat untuk menganalisis perkembangan para tokoh Islam yang mendukung ide kebebasan dan kemajuan. Beberapa tokoh yang terkenal di Indonesia adalah Leonard Binder dan Charles Kurzman.

Dawam Raharjo ${ }^{1}$ menganggap bahwa negara-negara Barat yang berakar pada trilogi liberalisme, pluralisme, dan sekularisme, berperan dalam perkembangan ilmu pengetahuan, teknologi, dan ekonomi. Atas dasar itulah ia dan beberapa tokoh Islam liberal lainnya ingin membangkitkan semangat umat Islam untuk mencapai kemajuan dengan mengangkat pemikiran tersebut. Tetapi dalam perjalanannya, ia mendapat kritikan tajam yang menimbulkan polemik (Rachman: 2018: xv), seperti yang dialami oleh Nurcholish Madjid dan Harun Nasution yang dikritik H.M Rasjidi, serta tokoh muda Ulil Abshar Abdalla dan Budi Munawar Rachman yang dikritik oleh Atiyan Ali M. Dai dan Adian Husaini. Puncaknya keluarlah fatwa MUI yang mengharamkan liberalisme.

\footnotetext{
1 Dawam Raharjo adalah salah satu tokoh senior Islam liberal yang menjadi inspirator tokoh muda Islam Liberal di Indonesia (Rahman, 2010: 28).
} 
Berdasarkan persoalan tersebut maka muncullah pertanyaan bagaimana gambaran sejarah masuknya Islam liberal di Indonesia dan mengapa terjadi polemik Islam liberal di Indonesia?

Kriteria tokoh Islam liberal yang dibahas dalam tulisan ini adalah para tokoh yang memiliki karya ilmiah mengenai Islam liberal dan dipublikasikan dalam jurnal atau buku tentang paham tersebut. Kedua, memiliki kedalaman ilmu dan wawasan tentang Islam Liberal. Ketiga, mendukung sebagian besar paradigma Islam Liberal. Keempat, memiliki pengaruh besar terhadap masyarakat baik pro maupun kontra terhadap Islam Liberal. Kelima, mewakili latar belakang paham keagamaan, pendidikan, geografis, dan berbagai generasi.

Beberapa karya yang dijadikan rujukan dalam penulisan karya ini adalah karya Greg Barton dan Zuly Qodir, yang mendukung Islam liberal. Lalu karya Adian Husaini dan Fauzan Al-Anshari, yang menolak Islam liberal di Indonesia.

Greg Barton menulis Gagasan Islam Liberal di Indonesia (Pemikiran neoModernisme Nurcholish Madjid, Djohan Efendi, Ahamad Wahib, dan Abdurahman Wahid) pada 1999. Fokus tulisannya pada keempat tokoh yang menjadi kontributor utama Islam liberal. Semua peristiwanya terjadi pada 1960-1990an dan tokoh tersebut lahir dari neo-Modernis.

Selain tokoh yang diteliti oleh Greg Barton, ada beberapa tokoh utama Islam liberal lainnya, seperti Harun Nasution, Dawam Raharjo, Mukti Ali, dan Syafii Maarif. Karya Greg Barton memiliki keterbatasan karena fokus pada empat tokoh Islam Liberal. Sedangkan, penelitian penulis fokus pada 50 tokoh Islam liberal.

Zuly Qodir (2012) dalam, Islam Liberal: Varian-Varian Liberalisme Islam di Indonesia 1991-2002 diterbitkan oleh LkiS berupaya memotret latar belakang munculnya gerakan pemikiran Jaringan
Islam Liberal (JIL) ${ }^{2}$. Zuly lebih banyak menggunakan pendekatan sosiologi untuk memotret gerakan pemikiran di kalangan umat Islam di Indonesia. Fokus kajian karya penelitian dengan perspektif sosiologi tampaknya kurang lengkap, karena untuk mengetahui sejarah pemikiran liberal perlu dibuka dengan berbagai perspektif. Seperti yang dilakukan penulis yang menggunakan perspektif sejarah, antropologi, sosiologi, dan psikologi.

Selanjutnya karya Adian Husaini (2002), yang berjudul: Islam Liberal: Sejarah, Konsepsi, Penyimpangan, dan Jawabannya. Dalam buku itu, ia menguraikan alasan mengapa Islam liberal patut diwaspadai dan ditentang. Dari uraiannya cenderung menghakimi. Hal ini terlihat dari penggunaan kalimat "penyimpangan". Isinya sendiri adalah kumpulan kritik terhadap keberadaan tokoh-tokoh Islam liberal dan perguruan tinggi Islam. Sedangkan penulis menghindari kalimat-kalimat yang cenderung menghakimi. Tetapi kontribusinya dibutuhkan untuk mengimbangi pemikiran yang menolak Islam liberal.

Selanjutnya hasil penelitian Fauzan Al-Anshari (2003), Pengurus Majelis Mujahidin Indonesia (MMI), dengan judul Melawan Konspirasi JIL (Jaringan Islam Liberal). Ia menulis kritik atas Islam liberal yang menjadi anggota organisasi JIL. Menurut hasil penelitiannya, Jaringan Islam Liberal (JIL) adalah organisasi yang menggunakan jargon kebenaran untuk mengelabui masyarakat. Jargon JIL

\footnotetext{
2 Jaringan Islam Liberal (JIL) yang didirikan pada 8 Maret 2001 dengan koordinatornya Ulil Abshar Abdalla dan anggotanya, antara lain: Luthfi Assyaukanie, Nong Darol Mahmada, Novriantoni, Burhanuddin Muhtadi, Rizal Malaranggeng, Saeful Mujani, Hamid Basyaib, Taufiq Adnan Amal, Syamsu Rizal Pangabean, Ahmad Sahal, Budi Munawar-Rahman, dll (Pribadi dan Haryono, 2002 :288; Rachman, 2018a: 46). Adapun tujuannya untuk mendukung pemikiran Islam Liberal.
} 
mengatasnamakan kebebasan, persamaan hak asasi manusia, dan kebersamaan.

Berdasarkan penjelasan tersebut buku ini merupakan kumpulan kritik dan bantahan terhadap seluruh pemikiran dan aktivitas Jaringan Islam Liberal. Tulisannya sangat subjektif, bahkan cenderung kasar seperti memplesetkan Jaringan Islam Liberal dengan "Jaringan Iblis liberal". Terjadi pada peristiwa polemik penulisan Ulil Abshar Abdalla di Harian Umum Kompas dan melihat JIL dengan perspektif yang menolak seluruh pemikiran Islam liberal (Al-Anshari, 2003).

Penelitian mengenai Islam liberal masih belum banyak dikaji di Indonesia. Melalui tulisan ini, diharapkan masyarakat memahami tentang paradigma Islam liberal mulai dari proses pengenalan pemikiran, terbentuknya paradigma Islam liberal, kritik terhadap pemikirannya, hingga terjadi evaluasi pemikiran Islam liberal.

\section{B. METODE PENELITIAN}

Metode yang digunakan adalah metode sejarah, yang meliputi; heuristik, kritik, interpretasi, dan historiografi. Dalam proses heuristik, penulis mendapatkan sumber-sumber di antaranya: Arsip Forum Ulama Umat Indonesia (FUUI) (2002) tentang hukumam mati bagi Ulil Abshar Abdalla sebagai efek dari tulisan Ulil Abshar Abdalla (8 November 2002) dalam HU Kompas yang menimbulkan polemik. Arsip Majalah Panji Masyarakat (1984) tentang (Munawir Sjadzali, Abdurrahman Wahid, dan, M. Dawam Raharjo) pada 2016, dan arsip hasil Munas MUI 11 Fatwa (2005) yang mengharamkan Islam. Selanjutnya melakukan kritik, dan interpretasi terhadap sumber-sumber tersebut. Setelah dikritik dan diintepretasi, ditulis dalam laporan sejarah, yang disebut historiografi.

\section{HASIL DAN BAHASAN \\ 1. Sejarah Munculnya Pemikiran Islam Liberal di Indonesia \\ Para ahli belum mencapai} kesepakatan mengenai kapan munculnya pemikiran Islam liberal di Indonesia. Meskipun begitu, embrionya sudah muncul dalam kebijakan politik Pemerintah Belanda masa kepemimpinan Daendels 1808-1811. Salah satu buktinya, ia memberikan kesempatan mengenyam pendidikan. Dampaknya adalah para bumiputera memperoleh pendidikan modern dan melahirkan elit yang memiliki kesadaran nasionalisme (Abdullahan dan Herlina, 2012: 235).

Setelah berakhir pemerintahan Daendels, Raffles ${ }^{3}$ menggantikannya pada 1811 sebagai Gubernur Jenderal. Beliau melakukan liberalisasi dalam bidang pemerintahan, penghapusan ikatan feodalisme di dalam dan luar Jawa serta memberi kepastian hukum di kalangan masyarakat.

Setelah Indonesia merdeka, dalam bidang politik muncul sistem demokrasi liberal, yang memberikan kebebasan berideologi, terutama ideologi partai, seperti Partai Majelis Syuro Musliman Indonesia (Masyumi) yang mewakili ideologi Islam, Partai Sosialis Indonesia (PSI) yang mewakili Ideologi Sosialis Maxis, dan Partai Nasionalis Indonesia (PNI) yang mewakili golongan nasionalis "sekuler". Mereka bergabung di parlemen dengan ideologi yang berbeda-beda. Akibatnya terjadi perdebatan ideologi di Majelis Konstituante, terutama antara kelompok ideologi Islam dan Pancasila. Dalam kondisi tersebut, Presiden Soekarno

\footnotetext{
3 Diambil dari Buku Indonesia dalam Arus Sejarah (IDAS) 4 yang menjelaskan kebijakan liberalime Raffles ketika terjadi peralihan kekuasaan dari Belanda ke Inggris maka Raffles ditunjuk menggntikan Daendels memimpin Hindia Belanda (Suhartono dalam Taufik Abdullah dan Nina Herlina Lubis, et al (editor) 20124 h:158 dan 168).
} 
mengeluarkan Dekrit Presiden tahun 1959 yang isinya kembali pada UUD 1945 dan demokrasi liberal diganti dengan demokrasi terpimpin (Yatim, 1993: 265268).

Terlepas dari pembahasan tentang munculnya paham liberal dalam bidang politik yang dilakukan Pemerintah Kolonial Belanda dan Inggris di Indonesia, terutama masa Daendels, Raffles, dan demokrasi liberal setelah kemerdekaan, sampai saat ini belum ada yang membahas secara khusus tentang sejarah liberalisme dalam bidang pemikiran, terutama dalam pemikiran Islam di Indonesia.

Perkembangan pemikiran Islam liberal dapat dilacak dalam berbagai gerakan pembaruan dan modernisme Islam di Indonesia pada akhir abad ke-20. Kemunculannya di Indonesia boleh dikatakan lebih belakangan dibandingkan di negara-negara Islam lainnya, seperti Mesir dan Pakistan yang lebih dahulu mengenalkan pemikiran ini (Bachtiar, 2017: 21).

Wacana pemikiran Islam liberal muncul kali pertama di Indonesia oleh Greg Barton dalam bukunya yang berjudul Gagasan Islam Liberal di Indonesia (Pemikiran neo-Modernisme Nurcholish Madjid, Ahmad Wahib, Djohan Efendi, dan Abdurahman Wahid) pada 1999. Semenjak itu, wacana pemikiran Islam liberal menjadi popular, yang kemudian diteruskan oleh Charles Kurzman dalam bukunya Liberal Islam dan oleh Ulil Abshar Abdalla yang tergabung dalam organisasi JIL (Barton, 1999, Kurzman, 2001, dan Hendra, 2008).

Sebagian tokoh liberal rata-rata mulai berkembang pada 1970-an, karena pada waktu itu, kaum intelektual Islam yang mendapatkan pengaruh pemikiran dari Timur Tengah dan Barat mulai muncul seperti Harun Nasution dan Abdurrahman Wahid. Dalam konteks ini keduanya mendapatkan banyak pengaruh dari pemikir liberal Mesir, seperti Ali Abdul Raziq, Rifaat Al-Tahtawi, dan Thaha Husein. Harun Nasution dan
Abdurrahman Wahid memiliki pengaruh paling mendalam dalam penyebaran pemikiran Islam liberal di Indonesia, terutama di IAIN dan Nahdhatul Ulama (NU) (Bachtiar, 2017: 43).

Kemudian pada masa awal pemerintahan Orde Baru secara sistematis melakukan "penyingkiran" para tokoh Masyumi dan membatasi ruang gerak tokoh Islam yang bergerak dalam bidang politik dengan cara menolak melakukan revitalisasi Partai Masyumi (Abdullah, 2012: 404). Secara tidak langsung, Pemerintah Orde Baru membolehkan Islam politik ada tetapi "dikebiri" atau dibatasi. Kebijakan lainnya dikeluarkan pada 1973 setelah pemilu 1971. Pemerintahan Soeharto melakukan fusi partai-partai Islam dan memberlakukan azas tunggal bagi semua partai dan ormas. Akibatnya sebagian partai dan ormas harus mengganti azasnya dari Islam ke Pancasila (Abdullah, 2012: 407).

Sementara di sisi lain Pemerintah Orde Baru banyak memerankan tokoh yang tergabung dalam Centre for Strategic and International Studies (CSIS) yang melibatkan tokoh Katolik, seperti pimpinannya Pater Beek S.J seorang Pastur kelahiran Belanda yang didukung oleh Ali Mutopo dan L.B. Murdani. Implikasi dari kebijakan pemerintah Orde Baru dipengaruhi kelompok CSIS sehingga menjadikan umat Islam merasa tertekan dan melahirkan tokoh yang kritis terhadap pemerintah (Syam, 2012: 409-410). Segala gerak gerik umat Islam dicurigai, seperti peledakan Candi Borobudur, kasus Haur Koneng, dan tragedi berdarah peristiwa Tanjung Priok yang mengakibatkan banyak korban dari umat Islam. Kemudian kebijakan lainnya, menjadikan Aceh sebagai Daerah Opearasi Militer (DOM), pelarangan pelajar menggunakan busana muslim dan pelarangan libur sekolah di bulan Ramadan, dan memasukkan aliran kepercayaan dalam GBHN (Abdullah, 2012: 409-410).

Melihat kondisi umat Islam pada 1970-1980-an, muncullah kesadaran baru 
akan perlunya perubahan strategi dalam memperjuangkan nasib umat Islam di tengah modernisasi dalam politik Pemerintah Orde Baru. Kalangan aktivis dan pemikir generasi muda mencari berbagai cara yang berbeda dengan para pendahulunya. Menurut Abdul Munir Mulkhan, pemikir generasi muda merupakan babak baru perjuangan umat Islam yang sebelumnya terkait dengan politik praktis bergeser ke pendekatan sosial ekonomi dan kultural (Abdullah, 2012: 411).

Gerakan pembaruan pemikiran Islam yang lebih dikenal dengan neomodernis lahir dari ketegangan antara umat Islam dengan pemerintah. Adapun tokoh utamanya adalah Nurcholish Madjid yang proaktif melakukan modernisasi dan mencari akses yang bersifat akomodatif terhadap pemerintahan Orde Baru. Neomodernis ini pertama kali muncul pada 1970-an digagas oleh Himpunan Mahasiswa Islam (HMI) serta IAIN (Abdullah, 2012: 412).

Munculnya Nurcholish Madjid merupakan embrio lahirnya pemikiran Islam liberal. Pemicunya diawali oleh pidatonya pada acara silaturahim Idul Fitri yang diselenggarakan HMI, PII, GPI (Gerakan Pemuda Islam), dan Persami (Persatuan Sarjana Muslim Indonesia) pada 3 Januari 1970. Dalam acara tersebut, seharusnya Alfian Tanjuang (seorang intelektual Muslim dari LIPI) sebagai pembicara, namun ia tidak dapat hadir. Sebagai penggantinya ditunjuk Harun Nasution namun juga tidak bisa hadir. Akhirnya Nurcholis Madjid yang menggantikan mereka berdua (Bachtiar, 2017: 44; Madjid, 2013: 247-248; Barton, 1999: 82).

Dalam pidatonya Nurcholish Madjid menyampaikan keadaan umat Islam yang jumud (mandek) akibat terus mengulangulang keinginan memperjuangkan berdirinya kembali negara Islam melalui partai Islam. Padahal kenyataannya mereka tidak dapat membangun citra positif dan simpatik. Oleh karena itu, ia mengusulkan satu jargon kontroversial "Islam Yes, Partai Islam No!" Dia juga mengusulkan agar umat Islam harus lebih mengutamakan kualitas daripada kuantitas, Islam yang harus diperjuangkan bukan organisasi seperti partai. Beliau mempertegas bahwa umat Islam perlu melakukan "sekulerisasi" pemikiran, berpikir bebas, dan terbuka. Agar sekulerisasi pemikiran terwujud, diperlukan kelompok pembaharuan yang liberal (Bachtiar, 2017: 44; Madjid, 2013: 247-248; Barton, 1999:82).

Pidato kontroversi Nurcholish Madjid, seputar sekulerisasi dan jargon "Islam Yes, Partai Islam No"! bagi media Tempo dan Pandji Masyarakat merupakan isu yang menarik, terutama bagi pembaca dari kalangan Islam maupun yang lainnya. Pernyataan Cak Nur menjadi menarik karena situasi politik yang tengah memanas. Umat Islam tengah berhadapan dengan romatisme menghidupkan kembali partai Islam yang mendukung berdirinya Orde Baru. Kelompok politik dari sayap Masyumi yang sudah berubah menjadi Partai Muslimin Indonesia (Parmusi), Nahdhatul Ulama (NU), Sarekat Islam, dan Perti (Partai Tarbiyah Islamiyah) tengah mengkonsolidasikan diri untuk ikut dalam perebutan kekuasaan di awal Orde Baru, terutama menghadapi Pemilu pertama pada 1971. Akan tetapi, ketika partai Islam ingin menghidupkan kembali politik Islam, pidato Cak Nur malah menyarankan tidak perlu lagi menghidupkan partai Islam (Bachtiar, 2017: 45).

Pernyataan Cak Nur tentang keharusan liberalisasi dan sekulerisasi umat Islam, semakin menambah panjang kritik atasnya. Mengenai liberalisasi, ia menyebut satu bab khusus di pidatonya "Liberalisasi: Pandangan terhadap ajaranajaran Islam saat ini." Pada bab itu ia menekankan bahwa pembaharuan harus dimulai dengan dua tindakan yang satu sama lain erat hubungannya, yaitu melepaskan diri dari nilai nilai tradisional, dan mencari nilai-nilai yang berorientasi masa depan. Orientasi pada masa lampau 
dan nostalgia yang berlebihan harus digantikan dengan pandangan ke masa depan. Untuk mencapai nilai-nilai masa depan, diperlukan suatu proses liberalisasi" (Madjid, 2013; 250; Bachtiar, 2017: 46).

Berdasarkan analisisnya atas kondisi yang menimpa umat Islam saat itu, ia mengusulkan harus adanya kaum intelektual liberal yang dapat mewujudkan usulnya. Intelektual liberal yang dimaksud bukan yang selama itu disebut sebagai kaum pembaru, seperti; Muhammadiyah, Al-Irsyad, dan Persatuan Islam. Madjid menganggap organisasi tersebut telah jumud dan berhenti menjadi pembaru (Madjid, 2013; 258-259).

Selanjutnya Cak Nur menulis makalah yang berisi anjuran untuk dilakukannya liberalisasi pemikiran Islam, salah satunya proses sekulerisasi. Pembaruan Islam yang terjadi kembali di tengah umat Islam membuat para peneliti memberikan istilah yang berbeda untuk Nurcholish Madjid. Muhammad Kamal Hasan (1987) mengistilahkannya "Gerakan Pembaruan" mengikuti istilah yang berkembang di media massa saat itu (Tempo dan Pandji Masyarakat). Charles Kurzman (2003) dan Zuly Qodir (2010) memberikan istilah "Islam Liberal". Sedangkan, para pengkritiknya seperti Daud Rasyid (1999) menyebutnya sebagai "Sekulerisasi Agama" (Bachtiar, 2017: 47).

Polemik yang berkembang luas melalui media seperti Tempo dan Pandji Masyarakat setelah pidatonya pada 1970 rupanya tidak membuat Madjid mencabut pernyataannya. la malah memperkukuh pendapatnya saat diundang menyampaikan Orasi Kebudayaan di Taman Ismail Marzuki (TIM) Jakarta pada 1972 oleh Dewan Kesenian Jakarta (DKJ) setelah sebelumnya pidato tahun 1970-nya direvisi dan diterbitkan kembali dalam Bulletin Arena tahun 1972. Judul orasinya "Menyegarkan Kembali Pemahaman Keagamaan di Kalangan Umat Islam Indonesia". Isi orasinya kurang lebih merupakan pengembangan lebih lanjut atas pidatonya terdahulu. Madjid menekankan pentingnya memperbarui cara berpikir umat Islam yang dianggap gagal menjawab tantangan modern sehingga pemikirannya tidak "laku" di kalangan generasi muda. Bahkan, ia menganggap banyak apologi peradaban modern yang menyebabkan umat Islam berpikir tidak kreatif dan tidak bisa menjawab tantangan zaman (Madjid, 2013; 289-290 Bachtiar, 2017: 48).

Di sisi lain, Mukti Ali dan Harun Nasution melakukan pengubahan atau pembaruan kurikulum IAIN 1973. Harun Nasution yang menjabat rektor IAIN Jakarta pada 1973 dan menawarkan paradigma dasar baru studi Islam di IAIN yang ditulis dalam bukunya; Islam Ditinjau dari Berbagai Aspeknya. Buku ini menandai perubahan orientasi IAIN dari pendekatan studi yang dianggap tradisional, berkiblat ke Universitas AlAzhar dan menjadi pusat studi Islam yang berorientasi ke pusat studi Islam. Kebijakan ini ditempuh sejalan dengan kebijakan modernisasi di segala bidang yang dicanangkan oleh Orde Baru (Bachtiar, 2017: 51).

Ide perubahan kurikulum ini berasal dari Menteri Agama Mukti Ali (19711978). la adalah akademisi yang dididik di Timur Tengah dan Barat dan pernah bersekolah di Al-Azhar, Mesir dan menyelesaikan pascasarjananya di Universitas McGill, Kanada. Kemudian, dia mengabdi di IAIN Yogyakarta. Pemikirannya lebih mendukung modernisasi yang tengah dicanangkan oleh pemerintah Orde Baru. Hal inilah yang menjadikan pilihan Soeharto jatuh kepadanya untuk melakukan modernisasi di bidang agama (Bachtiar, 2017: 51-52).

Mukti Ali dipilih sebagai menteri agama agar sejalan dengan program modernisasi yang tengah dijalankan pemerintah. Dalam konteks Pendidikan Tinggi Islam di Indonesia, ia menilai bahwa IAIN sangat kolot dan tradisional. Ia tertarik pada model kajian di McGill dengan pendekatan yang sistematis, rasional, dan meminjam istilahnya sendiri holistis; baik dari segi ajaran, sejarah, 
maupun peradabannya (Bachtiar, 2017: 52).

Kesadaran seperti itulah yang disosialisasikannya ketika dia pulang ke Indonesia. Selain Akademi Dinas Ilmu Agama (ADIA), lembaga yang pertama kali menjadi tempat mengajarnya yaitu STI (Sekolah Tinggi Islam) yang namanya sudah berubah menjadi PTAIN (Perguruan Tinggi Agama Islam Negeri) yang kemudian keduanya digabung menjadi IAIN (Institut Agama Islam Negeri) di Yogyakarta. Di sanalah ia memperkenalkan pendekatan studi Islam baru yang ia dapatkan di McGill, terutama dalam hal metodologi dan perbandingan agama. Saat diangkat menjadi menteri agama ia melakukan pembaharuan kurikulum di IAIN (Bachtiar, 2017: 53).

Pada tingkatan pengelola, ia bertemu dengan Harun Nasution yang saat itu belum lama menjadi pengajar di IAIN Jakarta setelah mendapatkan Ph.D-nya di Universitas McGill, Kanada. Pendapat Harun Nasution menurutnya hampir sama dengan dirinya mengenai Al-Azhar dan kurikulum IAIN. Dalam autobiografinya, menulis pandangannya tentang IAIN bahwa ia sudah siap dengan konsepnya, sejak masih di luar negeri, sudah mendengar kondisinya bahwa pemikirannya sangat sempit. Buku-buku karangan Muhammad Abduh tidak boleh diajarkan (Bachtiar, 2017: 53-54).

Ide pembaruan yang sama antara Mukti Ali dan Harun Nasution sangat berpotensi menjatuhkan pilihan kepada Harun Nasution sebagai Rektor IAIN Jakarta pada 1973. Saat itu posisi Harun pun memang sudah memadai, yaitu sebagai Wakil Rektor I yang membidangi masalah akademik. Setelah diangkat menjadi rektor, program yang segera dikerjakan Harun adalah mengubah kurikulum IAIN. Sebagai usulan, mata kuliah Pengantar Ilmu Agama (PIA) perlu dimasukkan sebagai titik masuk untuk membentuk paradigma berpikir mahasiswa tentang studi Islam yang tengah dilakukannya. Selain itu, dimasukkan mata kuliah Dirasah Islamiah 1-3 yang diambil dari buku yang diberi judul Islam Ditinjau dari Berhagai Aspeknya sebanyak dua jilid (Nasution, 2016; Bachtiar, 2017: 54).

Buku tersebut menjelaskan apa itu Islam. Ada dua belas bab dalam buku tersebut, yang masing-masing bab menjelaskan satu aspek dari Islam versinya sendiri. Aspek-aspek tersebut meliputi Islam sebagai bagian dari agama, esensi Islam, perkembangan sejarah Islam, aspek politik dalam Islam, lembaga-lembaga kemasyarakatan dalam Islam, hukum Islam, teologi Islam, filsafat Islam, mistisisme Islam, dan aspek perubahan dalam Islam. Melalui buku ini Nasution menjelaskan bahwa Islam memiliki dimensi yang beragam (Nasution, 2016: ix; Bachtiar, 2017: 55).

Dengan mengubah kurikulum, sebetulnya Nasution ingin mengubah IAIN agar menjadi rasionalis, tidak tekstualis dan berpikiran sempit. la tidak ingin seperti Al-Azhar yang selalu dikritiknya sebagai tidak rasional, terlalu menekankan hafalan dan tidak memberikan wawasan analitik terhadap mahasiswa. la mengidolakan cara belajar Islam seperti di Universitas McGill, tempatnya belajar selepas dari Mesir. Tentu saja kurikulum pun ia buat agar mendekati cara belajar Islam. Dia mengaku bahwa di sanalah ia menemukan Islam yang bercorak rasional, bukan irasional seperti yang ditemukannya di Indonesia, Makkah, dan Mesir. Ia menyimpulkan bahwa karakter pemikiran yang rasional itu ada dalam sejarah pemikiran Islam, yaitu Muktazilah. Karakter pemikiran inilah yang nantinya menggiring IAIN ke arah Islam liberal yang dianggap lebih baik oleh Harun daripada Islam yang tekstualis dan rasional. Ketika pergi ke McGill pada 20 September 1962, di situlah ia betul-betul puas belajar Islam dan baru melihat Islam bercorak rasional. Bukan Islam irasional seperti didapatkan di Indonesia Makkah, dan Al-Azhar. Ia bisa mengerti kalau orang berpendidikan Barat mengenal Islam dengan baik melalui buku karangan 
orientalis. Menurutnya bisa dimengerti mengapa orang tertarik Islam karena karangan-karangan orientalis. Sejak awal di McGill, ia sudah melihat pemikiran liberal Muktazilah maju sekali. Kaum Muktazilahlah yang dapat mengadakan satu gerakan pemikiran dan peradaban Islam (Nasution, 1996: 37; Bachtiar, 2017: 56-57).

la mengaku bahwa idenya untuk mengubah kurikulum ditolak oleh para tokoh senior IAIN seperti Ismail Yakub dan K.H. Bafaddal. Akan tetapi, dia juga mendapat dukungan dari para petinggi di lingkungan Departemen Agama yang juga sebagian besar lulusan dari McGill seperti Mulyanto Sumardi (Dirjen Pendidikan Tinggi Islam), Zarkawi Suyuti (Sekdirjen Bimas lslam), dan tentu Mukti Ali sebagai Menteri Agama. Karena dukungan itu, maka kemudian terjadi kompromi. Kurikulum yang ditawarkannya bisa berjalan, dan mata kuliah lama seperti tafsir, hadis, dan fikih tetap berjalan (Bachtiar, 2017: 57).

Walaupun harus melalui kompromi, akhirnya perlahan-lahan Harun melakukan pengubahan kurikulum yang sebelulmnya kebanyakan fikih oriented dan berisi ajaran yang bersifat normatif, kemudian berubah kurikulumnya menjadi lebih beragam dan rasional. Karakter pemikirannya inilah yang nantinya menggiring IAIN ke arah Islam Liberal

Terjadinya perubahan orientasi kurikulum UIN/IAIN ke arah Islam yang rasional dan liberal tidak lepas dari peran Harun Nasution yang bagi UIN Jakarta mempunyai posisi yang penting. Ia juga, telah menulis sejumlah buku teks seperti Islam Ditinjau Dari Berbagai Aspeknya yang menjadi buku rujukan wajib bagi mata kuliah yang diwajibkan terhadap seluruh mahasiswa IAIN/UIN seluruh Indonesia sehingga memengaruhi cara berpikir mahasiswanya menjadi liberal.

Perkembangan pemikiran yang dikembangkan oleh Harun Nasution dan yang dijelaskan sebelumnya oleh Nurcholish Madjid dan Mukti Ali.
Menghadirkan Islam yang lebih dinamis, sebagai upaya untuk menjawab tantangan zaman, terutama pada masa awal sampai pertengahan pemerintahan Orde Baru. Sebagaimana diketahui, selama pemerintahan Orde Baru umat Islam dimarjinalkan, yang semula hanya dalam bidang politik lambat laun masuk ke dalam berbagai bidang yang membuat umat Islam semakin tertekan. Seperti telah dijelaskan sebelumnya segala gerak gerik umat Islam dicurigai, seperti tragedi peristiwa Tanjung Priok, menjadikan Aceh sebagai Daerah Opearasi Militer (DOM), pelarangan menggunakan busana muslim, dan pelarangan libur sekolah di bulan Ramadan.

Setelah terjadi pembaharuan cara pandang umat terhadap pemerintah, begitu juga pihak pemerintah yang mulai mendekati tokoh Islam, terutama setelah ditetapkannya Pancasila sebagai azas tunggal, terjadi perubahan terhadap umat Islam, dengan mendukung ditetapkannya undang-undang peradilan agama, SKB tiga menteri untuk penanganan zakat, dan izin memakai busana muslim di sekolah, dan mendukung berdirinya ICMI. Pada periode itu terjadi integrasi antara pemerintah dan umat Islam. Mendekati akhir masa pemerintahannya, Soeharto banyak mengakomodasi tokoh Islam di pemerintahan, militer, dan DPR. Sehingga terkenal dengan slogan "ijo royo-royo" (Abdullah, 2012: 415-416).

Ketika umat Islam merapat dengan pemerintah Orde Baru, terjadi krisis ekonomi. Banyak perubahan yang terjadi. Termasuknya berakhirnya pemerintahan Orde Baru dan masuk masa reformasi yang dikenal dengan masa kebebasan dan keterbukaan dalam bidang sosial, politik, dan keagamaam. Para tokoh Islam yang sebelumnya mementingkan perjuangan kultural daripada struktural, mengikuti jejak Nurcholish Madjid dan Abdurrahman Wahid. Tetapi mereka malah terbawa arus dan mengubah pandangannya sehingga mereka dianggap tidak konsisten. 
Seperti Nurcholis Majdid dan kawan-kawannya, menurut Ulil Abshar Abdalla, mereka sudah tidak dinamis lagi. Setelah periode reformasi Cak Nur yang sebelumnya terkenal dengan semboyan Islam Yes, Partai Islam No, malah aktif mendukung partai Islam, Partai Keadilan Sejahtera (PKS). Begitupun Harun Nasution yang mengurangi peran akal, seperti aliran Mutazilah, dalam perjalanan hidupnya ia ikut menjadi jamaah Tarikat Qodiriyyah Naqsyabandiyah Abah Anom, Suryalaya Tasikmalaya. Abdurrahman Wahid yang terkenal dengan gagasan Islam sosial kultural tergoda masuk ke wilayah struktural dengan mendirikan partai politik dan menjadi Presiden RI. Ini menggambarkan bahwa mereka terutama Nurcholish Madjid dan Abdurahman Wahid masih menyimpan suatu imajinasi utopis untuk tujuan yang bersifat struktural sehingga pembaruan yang dilakukannya mengalami kemandegan. Kemudian Harun membatasi peran akal. Maka menurut Ulil Abshar Abdalla diperlukan terobosan baru untuk meneruskan gagasan Nurcholish Madjid, Abdurahman Wahid, dan Harun Nasution (Rachman, 2018: 38).

Terobosan baru

mengembangkan ide Islam liberal diteruskan oleh tokoh: Azyumardi Azra, Bahtiar Effendy, Komaruddin Hidayat, Masdar F. Masud, Moeslim Abdurrahman, Nasaruddin Umar, Said Aqil Sirajd, dan Zainun Kamal, M. Syafi'i Anwar, Ulil Abshar Abdalla, Budi Munawar Rachman, Abdul Muqsith Ghazali, Ahmad Sahal, Hamid Basyaid, Husein Muhammad, Ikhsan Ali Fauzi, Luthfi Assyaukanie, Maman Imanul Haq Faqieh, Nong Darol Mahmada, Siti Musdah Mulia, Taupik Adnan Amal, Zuhairi Misrawi, dan Zuly Qadir (Rachman, 2011:Ixxix).

Awal tahun 2000-an, Ulil Abshar Abdalla menuliskan pemikirannya di $\mathrm{HU}$ Kompas berjudul "Menyegar Kembali Pemahaman Islam”. Dia menjelaskan jalan satu-satunya menuju kemajuan Islam adalah mempersoalkan kembali cara menafsirkan ajaran agama. Untuk menuju ke arah itu kita memerlukan beberapa hal. Pertama, penafsiran Islam yang non-literal, subtansial, kontekstual dan sesuai dengan denyut nadi peradaban manusia. Kedua, penafsiran Islam yang dapat memisahkan mana kreasi budaya lokal dan mana nilai fundamental ajaran Islam. Ketiga, umat Islam hendaknya tidak memandang dirinya sebagai "masyarakat" atau "umat" yang terpisah dari golongan lain. Umat manusia adalah keluarga universal yang dipersatukan oleh kemanusiaan itu sendiri. Larangan kawin beda agama dalam hal ini perempuan Islam dengan non-Muslim sudah tidak relevan lagi. Alquran sendiri tidak pernah dengan tegas melarang itu, karena menganut pandangan universal. Keempat, umat Islam membutuhkan struktur sosial yang dengan jelas memisahkan mana kekuasaan politik dan mana kekuasaaan agama. Agama adalah urusan pribadi; sementara pengaturan kehidupan publik adalah sepenuhnya hasil kesepakatan masyarakat melalui prosedur demokrasi (Abdalla, 2002:4-5; Abdalla, Wawancara Tanggal 15 Februari 2018).

Selain Ulil, tokoh lainnya yang tampil di awal 2000an adalah Musdah Mulia. Dia menuliskan pemikirannya dalam sebuah buku yang berjudul "Islam Agama Rahmat bagi Alam Semesta". Dalam bukunya tersebut, dia berterusterang mendukung perkawinan sesama jenis, dengan argumen bahwa orientasi seksual sesama jenis baik itu homoseksual, lesbian, dan biseksual merupakan sebuah kodrati yang dalam fikih disebut dengan sunnatullah (sunnah Allah $)^{4}$. Dia berargumen bahwa yang dilarang dalam

\footnotetext{
${ }^{4}$ Sunatullah adalah mekanisme hukum (natur) alam yang berjalan secara natural. Tuhan tidak secara langsung mengatur perbuatan manusia, akan tetapi melalui hukum-hukum alam yang biasa terjadi. Misalnya kalau mau pintar dengan cara belajar, bukan dengan cara-cara lain yang bersifat irasional. Dalam sejarah Islam pendukung konsep Sunatullah ini dikembangkan oleh kaum Muktazilah (Nasution, 2002: 180).
} 
kitab suci lebih ditekankan pada perilaku seksualnya, bukan pada orientasi seksualnya. Sehingga jika hubungan sejenis atau homoseksual, baik gai maupun lesbian sungguh-sungguh menjamin kepada pencapaian-pencapaian tujuan dasar, maka hubungan demikian dapat diterima (Mulia, 2008: 3).

Selanjutnya gagasan Luthfi Asyaukanie, Siti Musdah Mulia, dan Ulil Abshar Abdalla didukung oleh tokoh muda Islam Liberal. Seperti: Zuhairi Misrawi, Taupik Adnan Amal, Mun'im A. Sirry, Hamid Basyaid, dan tokoh lainnya. Yang mendukung pemikiran liberalisme, sekulerisme, dan pluralsime.

\section{Polemik Pemikiran Islam Liberal}

Perkembangan Islam liberal dari 1970-an sampai masa reformasi mengalami perkembangan yang pesat, yang salah satu penyebabnya didukung oleh kebijakan pemerintahan yang memberi kebebasan. Maka 2001 terbentuk organisasi Jaringan Islam Liberal (JIL) yang bertujuan menyampaikan gagasan Islam melalui organisasi. Kemudian muncul tokoh-tokoh muda Islam liberal.

Untuk melihat situasi itu Charles Kurzmanb (2003: 492) dan tokoh-tokoh Islam liberal Indonesia membuat paradigma Islam Liberal di Indonesia dijelaskan enam paradigma Islam Liberal di Indonesia, dengan enam paradigma, antara lain: Pertama, kebebasan berpikir; Kedua, gagasan kemajuan; Ketiga penolakan terhadap teokrasi; Keempat, mendorong demokrasi; Kelima, pluralisme dan dialog dengan non-Muslim; dan Keanam, menjamin hak-hak perempuan.

Setelah terbentuknya paradigma Islam liberal itu, sebagian besar tokohtokohnya sepakat dengan paradigma itu, walaupun sebagian lagi menolaknya. Kemudian dari kelompok penentang Islam liberal semakin mempertegas kritikan gagasan tokoh-tokoh Islam Liberal itu, seperti Nurcholish Madjid yang sebelumnya mendapat kritikan keras dari Muhammad Natsir, H.M. Rasjidi,
Muhammad Naquib Al-Attas, dan Daud Rasyid. Kritikan dimulai dengan tokoh
senior Nurcholish Madjid, yaitu Muhammad Natsir yang mengkritiknya. Natsir sebelumnya mengharapkan dia menjadi penerusnya. Tetapi kecewa ketika Nurcholish Madjid menyampaikan ide-ide pembaruan, yang menurutnya akan menjauhkan diri dari aqidah dan cita-cita umat Islam (Bachtiar, 2017: 98-99).

Setelah mendapat kritikan dari Muhammad Natsir dan tokoh Masyumi, Nurcholish Madjid menjelaskan kembali bahwa gerakan-gerakan politik Islam melalui partai-partai Islam, yang salah satunya dipimpin oleh Muhammad Natsir, di awal kemerdekaan, sampai dengan awal Orde Baru yang lebih menekankan pada aspek ideologis, telah menyebabkan fungsi kultural Islam mengalami kehilangan tempat. Karena itulah, perjalanan Islam di Indonesia harus dimulai dari perjuangan kultural yang pada waktu itu dianggap sesuatu yang baru (Madjid, 1986).

Selanjutnya tokoh senior lainnya adalah H.M. Rasjidi yang secara serius menolak gagasan Nurcholish tentang sekulerisasi. Ia menilai bahwa pemikiran sekuler akan melenyapkan peranan agama sebagaimana yang telah terjadi di negaranegara lain di Barat. Walaupun tujuannya untuk memperbaiki nasib umat Islam, dengan menyesuaikan kepercayaan dengan realitas yang ia lihat sehari-hari namun pilihannya pada sekulerisasi adalah langkah yang salah (Bachtiar, 2017: 103; Rachman, 2018: 349 dan 351).

Kemudian tokoh Muhammad
Naquib Al-Attas yang mengkritik
Nurcholish Madjid yang mengatakan
sekulerisasi pasti terkait dengan
sekularisme sehingga tidak bisa dipisahkan
dengan pengalaman Barat yang
mencetuskan ide sekularisme. Menurutnya
ada tiga ciri paham sekuler, yaitu, seluruh
kehidupan di dunia (terutama bidang
sosial, politik, dan budaya) harus
dikosongkan dari makna rohaniah yang
menghubungkan dengan peran Tuhan.


Kedua, sebagai konsekuensi dari yang pertama, segala bentuk kewibawaan dari alam rohani harus ditolak. Ketiga, menafikan pandangan mutlak. Ketiga ciri paham sekuler itu bertentangan dengan ajaran Islam, karena sebaliknya segala sesuatu yang dilakukan umat Islam harus berkaitan dengan rohaniah (Al-Attas, 1987: 16).

Selanjutnya kritikan datang dari ahli Hadist UIN Syarif Hidayatullah Jakarta Daud Rasyid yang mengatakan Nurcholisd Madjid itu sudah keluar dari ajaran Islam karena menghilangkan identitas Islam itu sendiri. Dengan pemikiran sekulerisasi dan pendapat-pendapatnya yang mempersoalkan sesuatu yang sudah pasti, seperti kebanyakan umat Islam mengatakan bahwa "Tiada Tuhan selain Allah" diubah menjadi "tiada tuhan selain Tuhan," itu telah melakukan tasykik (meragukan), tasywih (mengaburkan), tadhlil (menyesatkan), dan tahrif (menyelewengkan) ajaran Islam. Karena alasan-alasan itu, Daud Rasyid mengatakan Nurcholish Madjid telah "sesat" (Bachtiar, 2017: 136-137).

Kritikan dari H.M. Rasjidi, Muhammad Naquib Al-Attas, dan Daud Rasyid dijawab Nurcholish Madjid dengan menjelaskan bahwa Islam sebagai agama yang paling sekuler dalam sejarah kehidupan manusia, karena memiliki konsep monotheisme yang keras mendesakralisasikan dan mendevaluasikan tuhan-tuhan selain Allah. Dengan kata lain apa yang dipandang manusia selama ini dianggap sakral, disekulerisasikan. Jadi jangan diartikan meninggalkan kehidupan politik dari agama atau mencopot agama dari kehidupan sosial. Sebaliknya sekulerisasi pemurnian paham ketuhanaan dengan meninggalkan apa-apa yang sebelumnya dianggap Tuhan (Madjid, 1987).

Selain tokoh Nurcholish Madjid yang mendapat kritik dari berbagai generasi, ada tokoh lain, yaitu Harun Nasution yang menjadi kontroversi karena gagasannya membangun suatu teologi
Islam yang rasional atas dasar pemikiran neo-Muktazilah (Rachman, 2011: Ixxviii; Nasution: 1986).

Menurutnya kemunduran umat Islam diakibatkan oleh teologi fatalistik yang semuanya diserahkan kepada Tuhan. Untuk itu perlu diubah dengan teologi yang dinamis yang bisa melahirkan produktivitas, serta memberikan kebebasan manusia seperti Muktazilah dan Qadariyah yang memberikan peran besar pada akal manusia (Nasution, 1996: 6; 111-113; Hidayat 2014: 335-336).

Semua gagasan Harun yang rasional dan mendukung kebebasan berpikir itu dituangkan dalam bukunya yang berjudul Islam Ditinjau dari Berbagai Aspek, mendapat kritik keras dari H.M. Rasjidi yang dituangkan dalam bukunya yang berjudul Koreksi Terhadap Dr. Harun Nasution tentang Islam Ditinjau dari Berbagai Aspeknya sebagai bentuk kritikanya terhadap pemikiran Harun. Dia berharap karyanya akan membuka cakrawala baru dari cara berpikir umat Islam Indonesia dalam menghadapi aliran dan idologi yang bermacam-macam (Rasjidi, 1977: 13-14; Husaini: 2010: 61).

Dalam buku itu, Rasjidi mengatakan bahwa Buku Harun Nasution menunjukkan terpengaruh metode orientalis Barat sehingga menganggap Islam sebagai suatu gejala masyarakat yang perlu menyesuaikan diri dengan peradaban Barat. Dengan begitu, akan hilanglah identitas Islam, dan akan hilang kekuatan jiwa yang kita peroleh dari Alquran. Buku tersebut menjelaskan bahwa agama Islam harus diubah penafsirannya sehingga sesuai dengan peradaban Barat itu (Rasjidi, 1977: 148-149; Rachman, 2011:Ixxviii).

Setelah polemik-polemik yang dialami tokoh senior Islam liberal, seperti yang dialami Nurcholish Madjid dan Harun Nasution, pada periode berikutnya, terutama awal 2000-an, giliran Ulil Abshar Abdalla dengan organisasinya yang bernama Jaringan Islam Liberal (JIL)

Ulil Abshar Abdalla sebagai Kordinator JIL menulis artikel di H.U 
Kompas yang menyatakan tidak ada yang namanya "hukum Tuhan" dalam pengertian seperti dipahami kebanyakan orang Islam. Misalnya hukum Tuhan tentang pencurian, jual beli, pernikahan, pemerintahan, dan sebagainya. Yang ada adalah prinsip-prinsip universal yang dalam tradisi pengkajian hukum Islam klasik disebut maqashidusy syari'ah atau tujuan umum syariat Islam (Abdalla, 2001:4). Pernyatan ini mendapat kritikan tajam dari berbagai kalangan.

Majelis Mujahidin Indonesia (MMI) mengkritik Ulil Abshar Abdalla dengan organisasi JIL yang dianggap akan "memberangus" Islam yang kafah (Islam yang menyeluruh), maka mereka memelesetkan Jaringan Islam Liberal dengan "Jaringan iblis Liberal" karena secara etimologi iblis berarti pembangkangan (noun) sedangkan pekerjaannya (verb) disebut ablasa yang artinya membangkang. Oleh karena itu menurut bahasa segala bentuk pembangkangan terhadap perintah Allah disebut iblis (Al-Anshari, 2003: 4).

Selanjutnya kritikan terhadap Ulil Abshar Abdalla dan organisasi JIL-nya yang mendapat tanggapan keras dan menimbulkan kontroversi di masyarakat adalah kritikan yang dilakukan oleh Ketua Forum Ulama Umat (FUU) Indonesia K.H. Athian Ali M. Dai, MA (Priode 20002005) dengan para ulama Jawa Barat, Jawa Tengah, dan Jawa Timur yang membuat pernyataan bersama bahwa Ulil Abshar Abdalla dalam tulisannya di Harian Umum Kompas tahun 2002 telah menghina Tuhan, Nabi Muhammad SAW, dan Islam itu sendiri sehingga Ulil bisa dihukum mati (FUUI, 2002: 2).

Selanjutnya pernyataan Ulil bisa dihukum mati diklarifikasi oleh pihak FUUI karena terjadi "kegaduhan" dan kesalahpahaman oleh media-media yang ada. Mereka menyatakan bahwa harus ada sangsi hukum yang jelas bagi pelanggar hukum yang berkualifikasi delik penghinaan agama seperti itu. Apabila syariat Islam diterapkan, oknum yang menghina dan yang memutarbalikkan kebenarana agama dapat diancam dengan hukuman mati (FUUI, 2002). Klarifikasi tersebut menunjukkan bahwa bukan K.H. Athian Ali yang mengancam hukuman mati terhadap terhadap Ulil Abshar Abdalla.

Selanjutnya setelah K.H. Atiyan Ali, muncul Adian Husaini yang mengkritik JIL dan para pemikir Islam Liberal. Ia mengatakan Islam Liberal merupakan pengaruh dari Barat yang sekuler dan menganggap kebenaran fundamental dari agama bisa disamakan dengan teoritis manusia. Kebenaran absolut dinegasikan dan nilai-nilai relatif diterima sehingga tidak ada kepastian. Konsekuensinya manusia diposisikan sebagai satu-satunya yang berhak mengatur dunia. Hal ini bertentangan dengan ijma' (kesepakatan ulama) mengenai pokok ajaran agama (Husaini, 2005:3; Bachtiar, 2017: 384).

Dengan pernyataan itu Adian Husaini ingin menjelaskan bahwa pemikiran Islam liberal sering masuk ke dalam persoalan yang sebelumnya sudah qat' $i$ (pasti) dari perintah Allah, tetapi dengan akalnya dipersoalkan kembali sehingga akan menimbulkan keraguan. Dengan demikian bisa dikatakan akal manusia lebih tinggi dari Tuhannya.

Setelah Ulil Abshar Abdalla, muncul tokoh Islam liberal berikutnya yang menimbulkan kontroversi, seperti yang dialami oleh; Siti Musdah Muliah, Luthfi Asyaukanie, Budi Munawar Rachman, Zuhairi Misrawi, Taupik Adnan Amal, Mun'im A. Sirry, Hamid Basyaid dan kawan-kawannya yang juga mendapat kritikan tajam dari berbagai kalangan.

Tokoh-tokoh Islam liberal itu mendapat kritik dari organisasi yang tidak secara khusus dibentuk untuk menghadapi kelompok Islam Liberal, seperti: FPI, MMI, FUUI, dan HTI. Selanjutnya ada organisasi yang secara khusus untuk menghadapi kelompok Islam Liberal, seperti Institut for the Islamic Thought and 
Covilization (INSISTS) ${ }^{5}$ dan Indonesia Tanpa JIL (ITJ) (Bachtiar, 2017: 156).

Setelah menimbulkan polemik dan kontroversi yang berkepanjangan, puncaknya keluarlah Fatwa MUI yang mengharamkan paham sekular, pluralisme, dan liberalisme. Isi fatwa tersebut adalah pluralisme agama adalah suatu paham yang mengajarkan bahwa semua agama adalah sama dan karenanya kebenaran setiap agama adalah relatif. Kedua, pluralisme agama adalah sebuah kenyataan bahwa di negara atau daerah tertentu terdapat berbagai pemeluk agama yang hidup secara berdampingan. Ketiga, liberalisme agama adalah memahami nas agama (Alquran dan Sunah Rasulullah) dengan menggunakan akal pikiran yang bebas. Keempat, sekulerisme agama adalah memisahkan urusan dunia dari agama (MUI, 2005: 20).

Keluarnya fatwa tersebut menyudutkan tokoh Islam liberal, karena tiga pilar utama Islam liberal, yaitu; sekulerisme, liberalisme, dan pluralisme diharamkan MUI. Itulah titik puncak polemik dan kontroversi wacana pemikiran Islam Liberal di Indonesia, baik yang setuju maupun yang menolaknya, karena fatwa itu akumulasi dari perdebatan panjang dalam sejarah pemikiran Islam Liberal di Indonesia. Peristiwa ini memengaruhi perkembangan pemikiran Islam liberal pada periode berikutnya.

Dari penjelasan di atas, polemik Islam Liberal terjadi diakibatkan oleh paradigma berfikir dan metodologi memahami ajaran Islam dalam melihat realitas yang terjadi di masyarakat pada masa koontemporer.

Perbedaan paradigma berpikir antara tokoh Islam liberal dan para pengkritiknya adalah adanya perbedaan dalam upaya untuk membangkitkan umat Islam dari

\footnotetext{
${ }^{5}$ Organisasi ini didirikan oleh para mahasiswa Indonesia yang sedang kuliah di Malaysia tahun 2003. Tokohnya antara lain: Adian Husaini, Hamid Fahmi Zarkasy, dan Adnin Armas
}

kemunduran. Menurut para tokoh Islam Liberal, hanya Islam liberallah yang akan memberikan jalan kemajuan umat Islam, seperti yang dijelaskan oleh Dawam Raharjo tadi di awal. Karena gerak sejarah terus maju secara progresif, dengan demikian diperlukan pemahaman terhadap wahyu yang lebih progresif dan rasional. Dalam Islam liberallah potensi dinamis itu besar. Cara pandang inilah yang dijadikan kerangka dasar Islam liberal dalam menyampaikan gagasannya. Sedangkan tokoh-tokoh pengkritik Islam liberal menggunakan kerangka berpikir neorevivalis, yang secara epistemologi berusaha untuk melakukan pembersihan Islam dari pemikiran dan praktik agama yang dianggap tidak sesuai dengan dasar Alquran dan Hadis. Selain perbedaan paradigma berpikir, terjadi juga perbedaan metodologi. Tokoh Islam liberal menggunakan metodologi hermeunetik dan rasional (tafsir bi-ra'yu) yang mencari makna-makna bahasa terhadap ajaran Islam. Serta membongkar kekudusan ajaran Islam. Sedangkan tokoh-tokoh penentang Islam liberal menggunakan metodologi yang berangkat dari wahyu yang disucikan melalui proses sejarah sehingga terjadi penyucian terhadap kandungan teksnya serta mengacu pada pemahaman teks secara mendalam. Selain itu, pendekatan tekstual (tafsir bil-ma'sur) juga digunakan sehingga setiap pendapatnya selalu di dasarkan pada teks yang terdapat dalam Qur'an dan Hadist apa adanya. Jadi yang dominan adalah pengertian bahasa (al-Qattan, 1987: 477484).

\section{PENUTUP}

Sejarah Islam Liberal di Indonesia melewati empat tahap, yaitu: Pertama, tahap awal yang masih menyatu dengan pemikiran Neo-Modernisme, yang terkenal dengan tokoh utamanya, yaitu Nurcholish Madjid, Abdurahman Wahid, Mukti Ali, dan Harun Nasution. Kedua, pembentukan paradigma Islam Liberal. Ketiga, kritik dan evaluasi terhadap tokoh Islam liberal, 
seperti yang dialami: Nurcholish Madjid dan Harun Nasution mendapat kritikan tajam dari H.M. Rasjidi, Al-Attas, dan Daud Rasyid. Kemudian Ulil Abshar yang dikritik Atiyan Ali dan Adian Husaini. Keritikan dari berbagai kalangan itu menimbulkan polemik yang berkepanjangan dikalangan umat Islam Indonesia.

Polemik pemikiran Islam Liberal diakibatkan oleh perbedaan paradigma berfikir dan metodologi memahami ajaran Islam dalam melihat realitas yang terjadi di masyarakat pada masa kontemporer. Kelompok Islam liberal memiliki paradigma berpikir progresif. Dalam Islam liberal potensi dinamis itu besar. Sedangkan tokoh-tokoh pengkritik Islam liberal menggunakan paradigma berpikir neo-revivalis, yang secara epistemologi berusaha untuk melakukan pemurnian Islam, dengan selalu berpegang pada dasar Alquran dan Hadist. Selain perbedaan paradigma berpikir, terjadi juga perbedaan metodologi. Di mana tokoh Islam liberal menggunakan metodologi hermuenetik dan rasional (tafsir bi-ra'yu) serta membongkar kekudusan ajaran Islam. Sedangkan tokohtokoh penentang Islam liberal menggunakan metodologi yang berangkat dari wahyu yang disucikan melalui proses sejarah sehingga terjadi penyucian. Kemudian menggunakan pendekatan tekstual (tafsir bil-ma'sur) sehingga setiap pendapatnya di dasarkan pada teks.

\section{DAFTAR SUMBER}

\section{Arsip}

FUUI. 2002

Arsip Pernyataan Bersama 'Ulama dan Umat Islam Jawa Barat, Jawa

Tengah Tengah, dan Jawa Timur. Pada tanggal 1 Desember.

Majelis Ulama Indonesia. 2005.

Arsip Fatwa MUI tentang Pluralisme, Liberalisme, dan Sekulerisme tahun 26-29 Juli 2005.

\section{Buku}

Abdullah, Taufik dan Nina Herlina. 2012. Indonesia dalam Arus Sejarah Jakarta: Ichtiar van Hoeve.

Abdullah, Taufik dan Fardaus Syam. 2012. Indonesia dalam Arus Sejarah Jakarta: Ichtiar van Hoeve.

Al-Anshari Fauzan. 2003.

Melawan Konspirasi JIL (Jaringan Islam Liberal), Jakarta: Pustaka alFurqan.

Bachtiar, Anwar. 2017.

Pertarungan Pemikiran Islam di Indonesia (Kritik-kritik Terhadap Islam Liberal dari H.M.Rasjidi Sampai INSIST). Jakarta: Alkautsar.

Barton, Greg. 1999.

Gagasan Islam Liberal di Insdonesia Pemikiran Neo-modernisme Nurcholish Madjid, Djohan Efendi, Ahamad Wahib dan Abdurahman Wahid.Terj. Nanang Tahqiq. Jakarta: Paramadina.

Echols, John M dan Hassan Shadly. 1987. Kamus Inggris Indonesia. Jakarta: Gramedia.

Hidayat, Asep, Samsudin, dan Dadan Rusmana. 2014. Studi Islam Asia Tenggara. Bandung: Pustaka Setia.

Husaini, Adian. 2005.

Wajah Peradaban Barat (Dari Hegemoni Kristen dan Dominasi Sekuler-Liberal). Jakarta: Gema Insani. 2010 Virus Liberalisme di Perguruan Tinggi Islam, Yogyakarta: Ombak.

Jatnika, Eka Hendra. 2008

Kontroversi Islam Liberal di Indonesia. Pontianak: STAIN Pontianak Press.

Kurzman, Charles. 2001. Wacana Islam Liberal: Pemikiran Islam Kontemporer Tentang Isuisu Global. Jakarta: Paramadina. 
Khalil al-Qattan, Manna. 1987.

Studi Ilmu-Ilmu Qur'an. Terjemahan Mudzakir AS. Bogor: Litera Antar Nusa.

Madjid, Nurcholish. 2013.

Islam $\mathrm{Ke}$ Moderenan dan Keindonesiaan. Bandung: Mizan.

Mulia, Siti Musdah. 2008.

Menuju Kemandirian Politik
Perempuan. Yogyakarta: Kibar Press.

Nasution, Harun. 1975.

Pembaharuan dalam Islam (Sejarah Pemikiran dan Gerakan). Jakarta: Bulan Bintang. 2002.

Teologi Islam. Jakarta: UI Press.

2016.

Islam Ditinjau dari Berbagai Aspeknya. Jakarta: UI Press.

1996.

Islam Rasional (Gagasan dan Pemikiran Prof Dr Harun Nasution). Bandung: Mizan.

Pribadi, Airlangga dan Y.R. Haryono. 2002. Post Islam Liberal (Membangun Dentuman Mentradisikian Eksperimentasi). Bekasi: Gugus Press.

Zuly Qodir. 2012.

Islam Liberal: Varian-Varian Liberalisme Islam di Indonesia 1991-200. Yogyakarta: LkiS.

Rachman, Budi Munawar. 2010.

Sekulerisme, Liberalisme, dan

Pluarlisme (Islam Progresif dan

Perkembanagn Diskursusnya). Jakarta:

Gramedia.

\section{1.}

Ensiklopedi Nurcholish

Madjid. Jakarta: Democracy

Project.

2018.

Reorientasi Pembaharuan Islam

Jakarta:The Asia Foundation.

Riswanto, Arif Munandar. 2010.

Buku Pintar Islam. Bandung: Mizan.
Rasjidi. 1972.

Koreksi Terhadap Drs Nurcholish Madjid Tentang Sekulerisasi. Jakarta: Bulan Bintang.

Yatim, Badry. 1993.

Sejarah Peradaban Islam. Jakarta: Raja

Grafindo Prasada Yogyakarta: Tiara Wacana .

\section{Surat Kabar dan Majalah}

Al-Attas, Naquib.

"Mengantar Sebuah Dialog Terbuka", dalam Panji Masyarakat, 21 Februari 1987.

Abdalla, Ulil Abshar.

"Menyegarkan Kembali Pemahaman Islam" yang di muat dalam $\mathrm{HU}$ Kompas, 8 November 2001.

Azra, Azyumardi.

"Faruki dan Studi Islam di Amerika", dalam Panji Masyarakat, 11 Juli 1986.

\section{Sumber Lisan/Informan}

Abdalla, Ulil Abshar. (51 Tahun). Pendiri dan mantan Kordinator Jaringan Islam Liberal (JIL). Wawancara di Bandung, 2018. 